Steel, R., J. TorRIE and D. Dickey (1997): Principles and Procedures of Statistics - a Biometrical Approach, $3^{\text {rd }}$ Edition. McGraw-Hill Series in Probability and Statistics, Boston.

TOLEDO, E. and C. RINCóN (1996): Utilización industrial de nuevas especies forestales en el Perú. Cámara Nacional Forestal, Instituto Nacional de Recursos Naturales, Organización Internacional de las Maderas Tropicales, Lima.

Weber, J. C., C. Sotelo Montes, H. Vidaurre, I. K. DaWson and A. J. Simons (2001): Participatory domestication of agroforestry trees: an example from the Peruvian Amazon. Development in Practice 11: 425-433.

WeBer, J. C. and C. Sotelo Montes (2005): Variation and correlations among stem growth and wood traits of Calycophyllum spruceanum Benth. from the Peruvian Amazon. Silvae Genetica 54: 31-41.
WeI, X. and N. M. G. Borralho (1997): Genetic control of wood basic density and bark thickness and their relationships with growth traits of Eucalyptus urophylla in south east China. Silvae Genetica 46: 245-250.

Wiemann, M. C. and G. B. Williamson (1989): Radial gradients in the specific gravity of wood in some tropical and temperate trees. Forest Science 35: 197-210.

Woodcock, D. W. and A. D. SHIER (2002): Wood specific gravity and its radial variations: the many ways to make a tree. Trees 16: 437-443.

ZHANG, S. Y. (1995): Effect of growth rate on wood specific gravity and selected mechanical properties in individual species from distinct wood categories. Wood Science and Technology 29: 451-465.

Zobel, B. J. and J. B. JeTt (1995): Genetics of Wood Production. Springer-Verlag, Berlin.

Zobel, B. J. and J. R. SpRAgue (1998): Juvenile Wood in Forest Trees. Springer-Verlag, Berlin.

\title{
Construction of Microsatellite Linkage Maps for Corymbia
}

\author{
By M. ShePherD ${ }^{1), 3)}$, S. KASEM ${ }^{1)}$, D. LeE $^{2)}$ and R. HenRY ${ }^{1), 3)}$
}

(Received 14 $4^{\text {th }}$ March 2006)

\begin{abstract}
The genus Corymbia is closely related to the genus Eucalyptus, and like Eucalyptus contains tree species that are important for sub-tropical forestry. Corymbia's close relationship with Eucalyptus suggests genetic studies in Corymbia should benefit from transfer of genetic information from its more intensively studied relatives. Here we report a genetic map for Corymbia spp. based on microsatellite markers identified de novo in Corymbia sp or transferred from Eucalyptus. A framework consensus map was generated from an outbred $\mathrm{F}_{\text {. }}$ population $(\mathrm{n}=90)$ created by crossing two unrelated Corymbia torelliana x C. citriodora subsp. variegata $\mathrm{F}_{1}$ trees. The map had a total length of $367 \mathrm{cM}$ (Kosambi) and was composed of 46 microsatellite markers distributed across 13 linkage groups (LOD 3). A high proportion of Eucalyptus microsatellites (90\%) transferred to Corymbia. Comparative analysis between the Corymbia map and a published Eucalyptus map identified eight homeologous linkage groups in Corymbia with 13 markers mapping on one or both maps. Further comparative analysis was limited by low power to detect linkage due to low genome coverage in Corymbia, however, there was no convincing evidence for chromosomal structural

\footnotetext{
1) Centre for Plant Conservation Genetics, Southern Cross University, PO Box 157, Lismore, NSW 2480, Australia. E-mail: shepher@scu.edu.au

2) Department of Primary Industries and Fisheries, Horticulture and Forestry Science, LB 16 Fraser Road, Gympie, QLD 4570, Australia.

3) Cooperative Research Centre for Sustainable Production Forestry, Southern Cross University, PO Box 157, Lismore,
} NSW 2480, Australia.
\end{abstract}

differences because instances of non-synteny were associated with large distances on the Eucalyptus map. Segregation distortion was primarily restricted to a single linkage group and due to a deficit of hybrid genotypes, suggesting that hybrid inviability was one factor shaping the genetic composition of the $\mathrm{F}_{2}$ population in this inter-subgeneric hybrid. The conservation of microsatellite loci and synteny between Corymbia and Eucalyptus suggests there will be substantial value in exchanging information between the two groups.

Key words: Corymbia torelliana; Corymbia citriodora subsp. variegata; genetic map; hybrid inviability; genetic marker; tree improvement; marker-aided selection.

\section{Introduction}

The development of genetic maps and a comparative analysis of maps amongst related plant groups has provided new insights into genome structure, organisation and evolution, with implications for plant improvement, gene pool conservation and management (NEWBURY and PAterson, 2003). Comparative studies are particularly valuable for commercial taxa which are resource poor in genetic information (eg. DNA markers or DNA sequence data) but where they have near relatives that are resource rich (BROwn et al., 2001). This situation exists for the genera Eucalyptus and Corymbia; most eucalypts of commercial importance belong to the genus Eucalyptus, the great majority of gene sequence and marker information is derived from a few Eucalyptus species, $E$. grandis, $E$. urophylla and $E$. globulus. The genus Corymbia has 113 species in 7 sections and includes 
important commercial taxa for forestry in the Section Politaria (i.e. spotted gums) and Section Cadagaria (Corymbia torelliana) (HILl and JoHnson, 1995; LEE, 2005), but for which there is comparatively little genetic information. A key question, therefore, is how relevant and to what extent genetic information can be transferred between the two taxa.

Comparative map analysis has revealed that high degrees of synteny (genetic loci are located upon the same chromosome) and colinearity (congruent ordering of loci on chromosomes) may exist for quite phylogenetically divergent groups in both plants and animals (BONIERBALE et al., 1988; LAGERCRANTZ and LydiATE, 1996; Moore et al., 1995; O'BRIEN et al., 1999). Amongst tree species, extensive synteny is evident in species of the genus Pinus, with little evidence for gross structural rearrangement amongst sub-sections of hard pines (Genus Pinus Subgenus Pinus) (Brown et al., 2001; DEVEY et al., 1999), including taxa that may have diverged as long as 70 MYA (KomULAINEN, 2003). Conservation of genome structure and organisation is also expected to be high amongst Eucalyptus sp. which should allow efficient exchange of genetic information within the genus (BRONDANI et al., 2002; MARQUES et al., 2002). Several recent comparative studies are supportive of no significant evidence of rearrangement amongst genetic maps of representatives from three sections of the subgenus Symphyomyrtus, section Latoangulatae (E. grandis), Maidenaria (E. globulus) and Exsertaria (E. tereticornis) (FREEMAN, 2006; MYBURG et al., 2003).

Eucalypts in the broad sense encompass three genera (Angophora, Corymbia and Eucalyptus). Corymbia (the bloodwoods and ghost gums) were initially classified as a subgenus within Eucalyptus but were given formal genus status in 1995 (HILL and JoHNSON, 1995). Although initially controversial, this reclassification has become widely accepted over the past decade as it conforms with phylogenetic relationships which show a basal dichotomy in the eucalypts with an Angophoroid clade (Angophora and Corymbia) and a nonAngophoroid clade (Eucalyptus s.s.) (HILL and JoHnson, 1995; LADIGES et al., 1995; STEANE et al., 2002; UDOVICIC et al., 1995). Fossil evidence suggests these major evolutionary lineages had diverged by the Middle Miocene (14-17 MYA) (HoLmes et al., 1983).

Physical genome characteristics of the two groups suggest there may be substantive differences in the organisation of the two genomes. The evidence available for DNA content indicates that Corymbia sp have around 1/2 the DNA content of a typical Symphyomyrt (i.e. E. globulus; E. grandis) (GRATTAPAGLIA and BRADSHAW, 1994). Differences in the karyotypes for the two groups, however, are subtle. All eucalypts have a haplotype chromosome number of 11 and extremely small uniform chromosomes (HAQUE, 1984). Detailed comparison of karyotype morphology has indicated that it is possible to distinguish $E$. maculata (now Corymbia maculata) from other Eucalyptus spp because of its more symmetrical karyotype (MATsumoto et al., 2000). The degree to which the difference in physical genome size impacts genome structure and organisation is unknown. For example, is the difference in genome size of Corymbia the result of a few major gross structural rearrangements (i.e. deletions) or are the changes more subtle, a consequence of smaller deletions dispersed throughout the genome? Recently, evidence for this second hypothesis was reported to explain differences in genome sizes between $E$. grandis and E. globulus (MYBURG et al., 2003).

This paper reports the first genetic map for Corymbia and a comparative analysis with published Eucalyptus grandis map. We report a consensus map based on two Corymbia torelliana x C. citriodora subsp. variegata $\mathrm{F}_{1}$ hybrid individuals. An outbred $\mathrm{F}_{2}$ population was selected for study because the $\mathrm{F}_{1}$ hybrid is of emerging commercial importance for tropical hardwood plantations in Australia, and the $\mathrm{F}_{2}$ is expected to segregate widely making it ideal for QTL detection experiments. The map was constructed from microsatellite markers developed de novo in Corymbia citriodora subsp. variegata (henceforth subsp. variegata) and by transference of markers identified in Eucalyptus spp.

\section{Methods}

\section{Mapping population}

The mapping population was an outbred $\mathrm{F}_{2}$ intersectional hybrid family. First, two unrelated $\mathrm{F}_{1}$ families were generated by hand pollinating two individuals of Corymbia torelliana (Section Cadagaria) individuals with pollen from two individuals of subsp. variegata (Section Politaria). An $\mathrm{F}_{2}$ was generated by intermating a select $\mathrm{F}_{1}$ from each family (Figure 1). Four hundred seed were sown in Queensland Department of Primary Industries and Fisheries, Gympie Glasshouse on the $12^{\text {th }}$ November 2004. Seed germination and early seedling survival was low with only 208 seedlings surviving on $31^{\text {st }}$ Jan 2005 and 154 surviving at 6 mths post-sowing. In January 2005, foliage was obtained from the 208 surviving seedlings, the two $\mathrm{F}_{1}$ parent trees and the four grandparents, and stored frozen at $-20^{\circ} \mathrm{C}$ until required for DNA extraction. A set of $90 \mathrm{~F}_{2}$, the two parents and four grandparents were used to study marker inheritance and segregation.

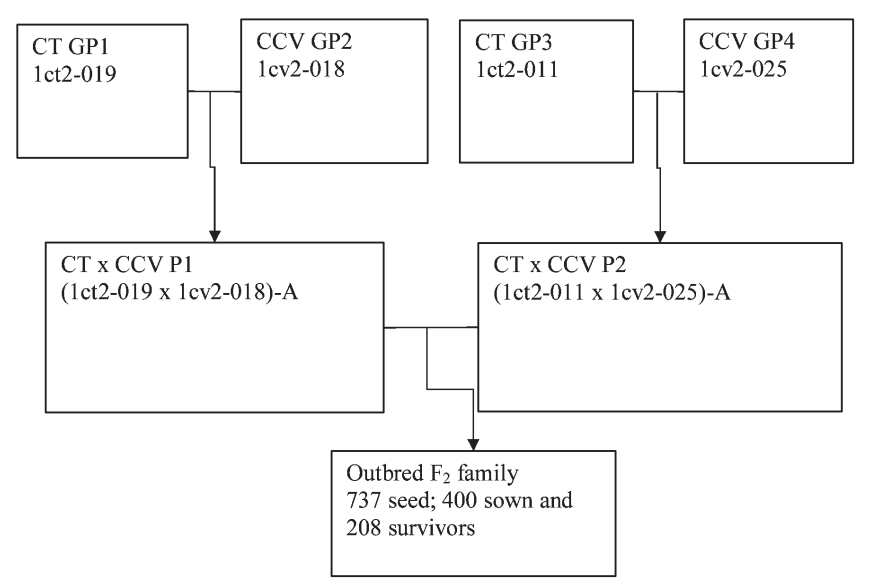

Figure 1. - Pedigree of C. torelliana x C. citriodora subsp. variegata outbred $\mathrm{F}_{2}$ mapping population. 1ct2-019 and 1ct2-011 were the C. torelliana maternal grandparents and 1cv2-018 and $1 \mathrm{cv} 2025$ the paternal $C$. citriodora subsp. variegata grandparents. (1ct2-011 x 1cv2-025)-A and (1ct2-019 x 1cv2-018)-A were the $\mathrm{F}_{1}$ parents crossed to form the $\mathrm{F}_{2}$ family. 


\section{DNA extraction}

DNA was extracted according to the frozen tissue protocol with the DNeasy 96 Plant kit (Qiagen $\mathrm{GmbH}$, Hilden, Germany) with the following modifications. The amount of tissue was reduced to $25-40 \mathrm{mg}$, PVP (2\%) was added to Buffer AP1 and the volume increased to 800 ul per sample. DNA was eluted into a final volume of $2 \times 100$ ul aliquots in Buffer AE.

\section{Microsatellite markers isolated from subsp. variegata}

Microsatellite loci were identified de novo in subsp. variegata. Primer sequences and methods used to isolate 14 of these loci have been previously described (JONES et al., 2001). A further 14 primer-pairs were developed for this study (Table 1). Suitability of loci for mapping and population studies was evaluated by amplifying each locus on a test panel of 21 individuals including the mapping pedigree and a set of 12 diverse subsp. variegata individuals. Polymorphism information content (PIC) for each marker was calculated using GenAlEx software (PEAKALL and SMOUSE, 2001).

Microsatellite markers transferred from Eucalyptus spp.

A set of 78 microsatellite loci identified in Eucalyptus spp. were evaluated for transfer to Corymbia spp. This set included 73 loci identified from a genomic library in
Eucalyptus grandis (BRONDANI et al., 2002; BRONDANI et al., 1998) and 5 loci identified in a genomic library of E. globulus (MorAN et al., 2004).

Transfer of Eucalyptus microsatellite loci was evaluated in two stages, firstly transfer to our laboratory and PCR conditions and secondly, transfer to the nonfocal taxa (i.e. species other than the species from which the microsatellite loci were isolated, in this study, Corymbia spp). Transfer was evaluated using a set of nine individuals, four grandparents, two parents and two offspring from the Corymbia mapping pedigree and an appropriate representative individual for the focal taxon. Markers were rated on five point scale where; $0=$ not transferred to our laboratory i.e. PCR failed on focal and nonfocal taxa, 1 = transferred to our laboratory i.e. PCR amplified in focal taxa only, 2 = transferred but segregation uncertain, 3 = transferred but not informative in mapping pedigree, $4=$ transferred and mapped.

\section{Microsatellite genotyping \\ PCR Amplification}

A standardised PCR reaction was used for all microsatellite loci primer-pairs. The PCR buffer contained a final concentration of $20 \mathrm{mM}$ Tris- $\mathrm{HCl}(\mathrm{pH} 8.4)$, $50 \mathrm{mM} \mathrm{KCl}$ (supplied as $10 \mathrm{X}$ PCR buffer, Invitrogen Life Technologies), $2.0 \mathrm{mM} \mathrm{MgCl}_{2}, 0.8 \mathrm{mM}$ dNTP (total

Table 1. - Primer sequences and properties for 14 microsatellite loci isolated from Corymbia citriodora subsp. variegata.

\begin{tabular}{|c|c|c|c|c|c|}
\hline Name & Oligo Sequence & Microsatellite repeat & $\mathrm{T}_{\mathrm{m}}{ }^{1}$ & $\begin{array}{l}\text { Allele } \\
\text { size } \\
\text { range }^{2} \\
\text { (bp) }\end{array}$ & $\overline{\mathrm{PIC}^{3}}$ \\
\hline \multirow{2}{*}{ EMCRC 41} & GACGGTAGCATTCTGTTCTTTGGCA & $(\mathrm{GA}) 24$ & 69.4 & $114-150$ & 0.89 \\
\hline & TGGGTCGACTTTCAAGTCGCGT & & 70.5 & & \\
\hline \multirow[t]{2}{*}{ EMCRC 44} & ССССАТСТССАТССТСТG & $(\mathrm{GA}) 24$ & 61.5 & $188-246$ & 0.28 \\
\hline & CGAACAACCCCCCATCT & & 61.8 & & \\
\hline \multirow{2}{*}{ EMCRC 45} & GCTAGGTTGGAACGAGCAAC & $(\mathrm{GA}) 18$ & 62.1 & 195-204 & 0.55 \\
\hline & TTGAGAAGAAGATGATATATAGCGTGA & & 61.5 & & \\
\hline \multirow{2}{*}{ EMCRC 46} & CCTTTGGAAGCATGCGTGT & $(\mathrm{GA}) 13$ & 64.6 & $151-202$ & 0.20 \\
\hline & СССТСССТАAGTCCACATGA & & 62.3 & & \\
\hline \multirow[t]{2}{*}{ EMCRC 47} & CCCACATAGAATCCCAACAT & $(\mathrm{AG}) 22$ & 59.5 & $185-217$ & 0.89 \\
\hline & CTCGGTACCTCTGCGAAAC & & 60.8 & & \\
\hline \multirow{2}{*}{ EMCRC 48} & TGGAAAATGACATAGGCGAAA & (AG)7AT(AG)24 & 62.6 & $080-132$ & 0.82 \\
\hline & CCGAACCAGAGAGTGGTG & & 60.2 & & \\
\hline \multirow[t]{2}{*}{ EMCRC 49} & ACCAAGAAACGGGGAAAGAG & $(\mathrm{GA}) 11(\mathrm{~A}) 7(\mathrm{GA}) 2$ & 62.6 & $251-286$ & 0.89 \\
\hline & GTTTTGGAGAGAGGGGCAAG & & 63.4 & & \\
\hline \multirow[t]{2}{*}{ EMCRC 51} & CTCGACCACCCGAGAGAA & $(\mathrm{GA}) 15$ & 62.5 & $250-277$ & 0.90 \\
\hline & CACAGAATTCACTCССТCCTAAA & & 61.7 & & \\
\hline \multirow[t]{2}{*}{ EMCRC 52} & AGTCGAGAACGGCAACTCTG & $(\mathrm{GA}) 18$ & 62.9 & $132-163$ & 0.87 \\
\hline & TCGCCCGTTTGCTTCTGT & & 65.3 & & \\
\hline \multirow[t]{2}{*}{ EMCRC 53} & CGGTAGCATTCTGTTCTTTGG & $(\mathrm{GA}) 25$ & 61.9 & $101-155$ & 0.88 \\
\hline & TTCTAGTCGCGTGAGTGTGG & & 62.5 & & \\
\hline \multirow[t]{2}{*}{ EMCRC 54} & AAAGACACCAGCTTGACAACTTC & (GA)19 & 62 & 073-107 & 0.91 \\
\hline & CAATAATGTGTGAGCGTATTCCTG & & 62.8 & & \\
\hline \multirow[t]{2}{*}{ EMCRC 55} & TGTAGATAAGGCGTGGAGAGG & $(\mathrm{GA}) 21$ & 61.5 & $270-297$ & 0.91 \\
\hline & GCATACAATTATCCGCCAGAG & & 61.7 & & \\
\hline \multirow[t]{2}{*}{ EMCRC 56} & TCCAAACCAAAACAACACCA & (GA)26 & 62.2 & $150-200$ & 0.75 \\
\hline & GCTCTCCCCACAGCATAGA & & 61.4 & & \\
\hline \multirow[t]{2}{*}{ EMCRC 93} & GCAACTCCAACGACAACAAC & $(\mathrm{GA}) 16$ & 61.6 & $131-166$ & 0.87 \\
\hline & GGTCAATCTCCTCCACCAGTAA & & 62.6 & & \\
\hline
\end{tabular}

${ }^{1} \mathrm{Tm}=$ Melting temperature of oligo determined by the thermodynamic method (RYCHLIK et al., 1990).

${ }^{2}$ Allele size range based on 3 C. torelliana and 12 C. citriodora subsp. variegata individuals.

${ }^{3} \mathrm{PIC}=$ polymorphism information content based on 12 C. citriodora subsp. variegata individuals. 
dNTPs), 0.02 U/ul Platinum Taq (Invitrogen Life Technologies) and $0.2 \mu \mathrm{M}$ each primer. Primers selected for mapping were resynthesised using a 5' fluorescent dye (6FAM, NED, VIC, or PET Applied Biosystems Foster City, CA or Sigma - Proligo, Lismore, Australia) for analysis using an Applied Biosystems 3730 Genetic analyser (Applied Biosystems). DNA templates were diluted to $0.4 \mathrm{ng} / \mathrm{ul}$ and a total of $2 \mathrm{ng}$ was used in a total reaction volume of $13 \mu \mathrm{l}$.

Microsatellite loci were amplified using a series of touchdown programs with annealing temperatures $\left(\mathrm{T}_{\mathrm{a}}\right)$ spaning $10^{\circ} \mathrm{C}$. The annealing temperature range was centred on the optimal Ta for each primer-pair. Optimal $\mathrm{T}_{\mathrm{a}}$ were determined as $5^{\circ} \mathrm{C}$ lower than the primer with the lowest melting temperature $\left(\mathrm{T}_{\mathrm{m}}\right)$. Primer thermodynamic $\mathrm{T}_{\mathrm{m}}$ were derived according to RYCHLIK et al. (1990) using the program Vector NTI (Informax, Frederick, MD USA) with parameters set to a primer concentration of $200 \mathrm{nM}$ and a salt concentration of $50 \mathrm{mM}$. As an example, a primer-pair with an optimal $\mathrm{Ta}$ of $55^{\circ} \mathrm{C}$ was assigned a program with an initial annealing temperature of $60^{\circ} \mathrm{C}$ which decreased to $50^{\circ} \mathrm{C}$ over 20 cycles, achieved by decreasing the temperature by $1^{\circ} \mathrm{C}$ every second cycle. Cycling was composed of a denaturation step of a $95{ }^{\circ} \mathrm{C}$ hold for $1 \mathrm{~min}$, a primer annealing step held at the annealing temperature for $1 \mathrm{~min}$, then a primer extension step of $72^{\circ} \mathrm{C}$ for $1 \mathrm{~min}$. This was followed by a further 20 cycles using the final annealing temperature. Cycling was preceded by a hold at $95^{\circ} \mathrm{C}$ for 5 min to provide a "hot start" and finished with a final hold of $3 \mathrm{~min}$ at $72^{\circ} \mathrm{C}$.

\section{Marker scoring and Map construction}

Marker loci were scored with the aid of GeneMapper V 3.5 software (Applied Biosystems). Grandparents and parents were genotyped for each marker to assist in identifying alleles. Once all markers had been scored, a marker phenotype rating of 1 to 3 was assigned to each marker based on its ease of scoring which was a function of allele separation and peak size.

Markers were coded for an outcrossing population for linkage analysis with JoinMap v 3.0 (Kyazma, Wageningen, The Netherlands) (VAN OOIJEN and VoORRIPS, 2001). Maps were prepared using the principles of framework and comprehensive maps; a framework map providing a map with a high confidence in grouping and order, whereas a comprehensive map reports linkages with a lower statistical support (KEATS et al., 1991). Separate framework maps were prepared for each $\mathrm{F}_{1}$ parent based on maternal and paternal data sets that contained loci informative for both parents as well as loci uniquely informative for the parent. Parental framework maps were generated with a grouping of LOD $=>3$ and with a interval support "Jump" value $<=2$ (decrease in Chi-square goodness of fit measure that may accompany the addition of a locus to an order. A large jump value indicates a poor fit; values of 3-5 are considered generally applicable (VAN OOIJEN and VoORRIPS, 2001)).

A consensus (sex- and taxa- averaged) framework and comprehensive map were generated for the two $F_{1}$ individuals by integrating the two parental data sets into a single data set. Joinmap integrates data from various segregation types and recombination estimates from a variety of sources into a single map. Maps of corresponding parental homologues are integrated where a group includes markers informative for both parents. Nonhomologous groups were identified by comparing maternal and paternal maps. Parental and grandparental data were excluded from the data set as Joinmap determines linkage phase automatically when calculating two-point linkage estimates. The framework consensus map was generated at grouping $\mathrm{LOD}=>4$ and an interval support Jump value $<2$. The comprehensive consensus map was obtained by "placing" "accessory" markers on to the framework map at the framework loci with the strongest linkage. Accessory markers were those that grouped with LOD support of at least 3 but could not be ordered at the stringent Jump value of less than 2. The comprehensive consensus map was prepared using MapChart 2.0 (VoORRIPS, 2001).

\section{Genome length estimates}

Genome lengths were estimated using the modification to Hulbert's method-of-moments approach (HULBERT et al., 1988), method 3 as given in CHAKRAVARTI et al. (1991) and observed genome coverage as per NELSON et al. (1994). Separate data sets were created for each parent composed of markers informative for the respective parent and recoded fully informative markers. Fully informative (3 and 4 allele) markers were recoded as backcross markers for both parents (markers segregating with only two alleles in an intercross were excluded from the analysis because of the low amount of information they provided) and pair-wise recombination estimates obtained from Joinmap's "Strong linkages tabsheet" when grouped at required LOD (Z) value. Joinmap LOD values are based on a $\mathrm{G}^{2}$ statistic for independence in a two-way contingency table, and are equivalent to standard LOD values where there is no segregation distortion in backcross markers (VAN OOIJEN and VOORRIPS, 2001).

\section{Results and Discussion}

Microsatellite markers developed de novo in subsp. variegata and transferred to C. torelliana

Primer-pairs for 14 newly developed microsatellite loci isolated from subsp. variegata amplified products of around the expected size in a test panel of subsp variegata and C. torelliana (data not shown). Polymorphism information content for the markers ranged from 0.2 to 0.91 with an average of $0.79 \pm 0.24$ for a set of 12 subsp. variegata individuals (Table 1). This average was comparable to the gene diversity for subsp. variegata assessed by microsatellites previously developed de novo from this taxa (av. $\mathrm{H}_{0}=0.86$ for 7 loci; (KING, 2004)) and with gene diversity based on microsatellites in other widespread eucalypts (BRONDANI et al., 1998; STEANE et al., 2001). Out of the 28 markers developed from subsp. variegata, 27 segregated in the mapping cross and tended to have high information content for mapping with 17 out of 28 loci segregating in both parents and having highly informative mating configurations with 3 or 4 
Table 2. - Amplification and transfer characteristics for Eucalyptus microsatellite loci in Corymbia sp.

\begin{tabular}{|c|c|c|c|c|c|c|}
\hline $\begin{array}{l}\text { Source } \\
\text { (Species/Library } \\
\text { type) }\end{array}$ & $\begin{array}{l}\text { No } \\
\text { transfer } \\
\text { to Lab. } \\
\left(\text { (O) }^{\prime}\right.\end{array}$ & $\begin{array}{l}\text { Focal } \\
\text { taxa } \\
\text { only } \\
\text { (I) }\end{array}$ & $\begin{array}{l}\text { Transfer } \\
\text { but } \\
\text { uncertain } \\
\text { seg. } \\
\text { (2) }\end{array}$ & $\begin{array}{l}\text { Not } \\
\text { informative } \\
\text { (3) }\end{array}$ & $\begin{array}{l}\text { Mapped } \\
\text { (4) }\end{array}$ & Total \\
\hline E. grandis - G & 32 & 4 & 1 & 6 & 30 & $\overline{73}$ \\
\hline E. globulus - G & 2 & 0 & ( & 0 & 3 & 5 \\
\hline Total & 34 & 4 & 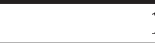 & 6 & 33 & 78 \\
\hline
\end{tabular}

${ }^{1}$ See methods for full description of classes.

segregating alleles (data not shown). Surprisingly, null alleles occurred at fewer loci (4) in C. torelliana parents of the mapping cross than subsp. variegata parents (5) suggested relatively little sequence divergence in priming sites between the two taxa. This was consistent with recent data from internal transcribed spacers (ITS) which suggested C. torelliana (Section Cadagaria) may be closer to the spotted gums (Section Politaria) than previously thought (Pers. Comm. J Ochieng). Based on $302 \mathrm{bp}$ of ITS1 and the 5.8 subunit, there was only $2 \mathrm{bp}$ substitutions between C. torelliana and subsp. variegata, yet, 5 and $6 \mathrm{bp}$ substitutions were found amongst members of the Politaria. All loci contained $(\mathrm{GA})_{\mathrm{n}}$ repeat types and were perfect except for EMCRC 48 and 49 (Table 1).

\section{Transfer and conservation of microsatellite loci from Eucalyptus}

A set of 78 microsatellite markers identified in Eucalyptus species were tested for transfer to Corymbia. Microsatellites were derived from two different species, 73 were identified in a genomic library of $E$. grandis (BRONDANI et al., 2002; BRONDANI et al., 1998) and 5 from a genomic library of an $E$. globulus individual (MORAN et al., 2004). A total of 44 out of the 78 loci were amplifi- able under the conditions used in this study (based on amplification of a PCR product of expected size from a representative of the focal taxa) (Table 2). Amongst loci that were amplifiable under the standardised conditions used in this study, $90 \%$ of loci transferred from Eucalyptus to Corymbia with more or less equal transfer to C. torelliana and subsp. variegata (Table 2). Although the sample size was small for E. globulus, transfer from E. grandis $(90 \%)$ to Corymbia sp appeared more successful than $E$. globulus $(60 \%)$. A review of cross trans-

Table 3a. - Map parameters for Corymbia genetic maps.

\begin{tabular}{l|rrrrr}
\hline Map & $\begin{array}{l}\text { No. } \\
\text { Markers } \\
\text { in }\end{array}$ & $\begin{array}{l}\text { LOD } \\
\text { Grouping }\end{array}$ & $\begin{array}{l}\text { No. } \\
\text { Mapped } \\
\text { Markers }\end{array}$ & $\begin{array}{l}\text { No. } \\
\text { Groups }\end{array}$ & $\begin{array}{l}\text { Map } \\
\text { Length } \\
\text { cMK }\end{array}$ \\
\hline $\begin{array}{l}\text { Maternal } \\
\text { Frame. }\end{array}$ & 54 & 3 & 42 & 13 & 399 \\
$\begin{array}{l}\text { Paternal } \\
\text { Frame. } \\
\begin{array}{l}\text { Consensus } \\
\text { Frame. }\end{array}\end{array}$ & 60 & 3 & 46 & 13 & 489 \\
$\begin{array}{l}\text { Consensus } \\
\text { Comprehensive }\end{array}$ & 64 & 4 & 47 & 13 & 367 \\
\hline
\end{tabular}

${ }^{1}$ Comprehensive map was based on a framework set of markers + accessory markers.

Table 3b. - Genome length and physical equivalent estimates for Corymbia.

\begin{tabular}{|c|c|c|c|c|c|c|c|c|}
\hline Map & $\begin{array}{l}\text { Grouping } \\
\text { criteria } \\
\text { (LOD) }\end{array}$ & $\begin{array}{l}\text { No. } \\
\text { Locus } \\
\text { pairs }\end{array}$ & $\begin{array}{l}\text { Max. } \\
\text { Dist. }\end{array}$ & Meioses & $\begin{array}{l}\text { Expected } \\
\text { genome } \\
\text { Length' } \\
\text { (cMK) }\end{array}$ & $\begin{array}{l}\text { Obs. No. } \\
\text { Groups }+ \\
\text { Unlinked } \\
\text { (L) }\end{array}$ & $\begin{array}{l}\text { Obs. } \\
\text { Coverage } \\
\text { (cM K) } \\
\text { and }(\%)^{2}\end{array}$ & $\begin{array}{l}\text { IC } \\
\text { physical } \\
\text { equivalent } \\
(\text { kbp) }\end{array}$ \\
\hline Symbol & $\mathrm{Z}$ & $\mathrm{K}$ & $\mathrm{X}$ & $\mathrm{M}$ & $\mathrm{E}(\mathrm{G})$ & $\mathrm{L}$ & $\mathrm{C}_{\mathrm{o}}$ & \\
\hline \multirow[t]{4}{*}{ Mat. } & 3 & 47 & 35 & 1081 & 1610 & $10+12$ & $784(49)$ & 236 \\
\hline & 4 & 39 & 31 & 1081 & 1719 & $9+16$ & $833(49)$ & 221 \\
\hline & 5 & 36 & 27 & 1081 & 1622 & $9+16$ & $696(43)$ & 234 \\
\hline & 11 & 20 & 15 & 1081 & 1622 & $1+42$ & $879(54)$ & 234 \\
\hline Av. & & & & & 1643 & & $798(48)$ & 231 \\
\hline \multirow[t]{4}{*}{ Pat. } & 3 & 58 & 35 & 1378 & 1663 & $10+12$ & $874(52)$ & 228 \\
\hline & 4 & 49 & 30 & 1378 & 1687 & $10+14$ & $879(52)$ & 225 \\
\hline & 5 & 46 & 24 & 1378 & 1438 & $10+15$ & $853(55)$ & 264 \\
\hline & 11 & 17 & 13 & 1378 & 2108 & $5+32$ & $827(39)$ & 180 \\
\hline Av. & & & & & 1724 & & $858(50)$ & 225 \\
\hline
\end{tabular}

${ }^{1}$ Genome Length $=\mathrm{E}(\mathrm{G})=2 * \mathrm{MX} / \mathrm{K}$ Hulbert's method-of-moments approach with Chakravarti method 3 modification (CHAKRAVARTI et al., 1991).

${ }^{2}$ Observed Map coverage, $\mathrm{C}_{\mathrm{o}}=\mathrm{G}_{\mathrm{f}}+\mathrm{X}(\mathrm{L}-\mathrm{R})$ where $\mathrm{R}=11$, the haploid chromosome number in Eucalptus and the $\mathrm{G}_{\mathrm{f}}$ for the maternal and paternal maps were 399 and 489 cM K respectively.

${ }^{3}$ Genome sizes used to estimate physical equivalents were taken from GRATTAPAGLIA and BRADSHAW (1994). Estimate for Corymbia hybrid genome size was $380 \mathrm{Mbp}$, the average of Corymbia torelliana and Corymbia maculata. 
ferability of microsatellites in a wide range of angiosperms and gymnosperms concluded that 30-40\% was typical for intergeneric (ROSSETTO, 2001), therefore our results suggest Eucalyptus and Corymbia are relatively close genera.
Although transfer may be high between the two genera, the information content of transferred loci may be lower than those identified de novo as only $30 \%$ of loci sourced from $E$. grandis and $20 \%$ from $E$. globulus where of the most informative mating configurations

\section{CM1a\&b}

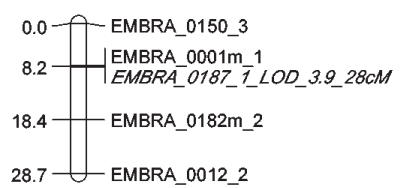

$0.0-6.6 \mathrm{EMCRC}+0054 \_1$
EMCRC_0033f3
EMBRA_0011_3_LOD_12_12CM

\section{CM2a\&b}

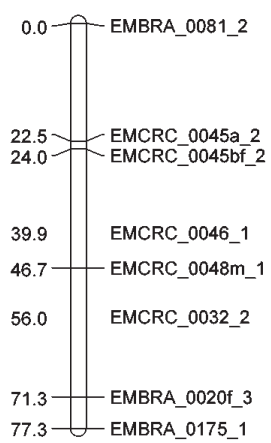

0.0 EMBRA_0104b

1.4- 3.4 EMBRA_0104a-2
CM3

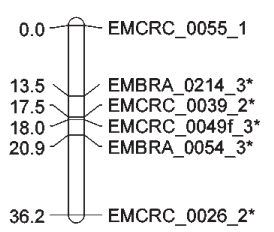

CM4

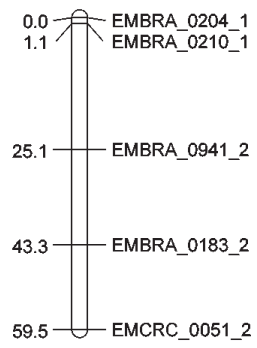

CM5

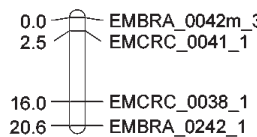

CM6

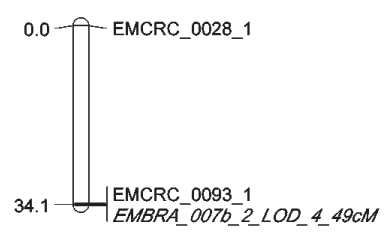

CM7

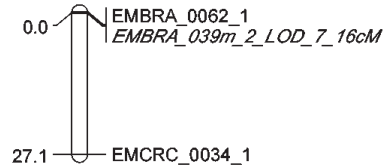

CM8

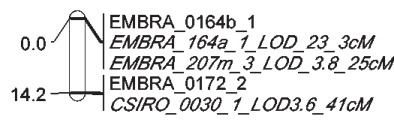

CM9

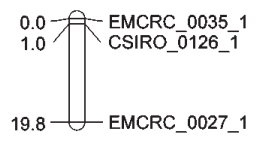

CM10

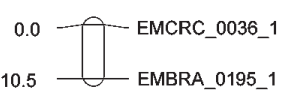

CM11

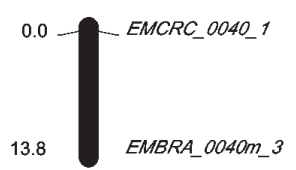

\section{CM12}

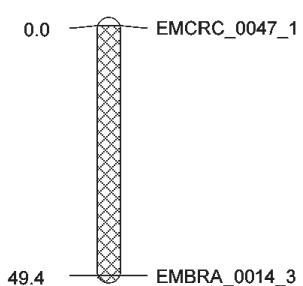

Figure 2. - A comprehensive consensus map for two Corymbia torelliana x citriodora subsp. variegata $\mathrm{F}_{1}$ hybrids. The total map distance was $417 \mathrm{cM}$ Kosambi, 47 framework and 9 accessory markers formed 12 Groups (LOD =>4; except CM12 (LOD 3)). Accessory markers are italicised and are reported at the framework loci that they were most strongly linked with their LOD and pair-wise distances. Groups CM11 and CM12 consisted of markers that segregated uniquely in the paternal or maternal parent respectively, and are highlighted with different shading. Groups CM1a\&b and CM2a\&b are linked at LOD 3 - indicated as separate groups but aligned vertically. Markers exhibiting segregation distortion are indicated by an asterisk $(\alpha \leq 0.05)$. A marker quality rating (1 to 3$)$ was suffixed to each loci, with 1 indicating the highest quality (see methods). 
with 3 or 4 segregating alleles in the mapping cross (data not shown).

Divergence in priming site sequence as indicated by the occurrence of null alleles, was concordant with phylogenetic relationships. Overall the number of loci with null alleles was high $(70 \%)$, with markers transferred from Eucalyptus showing a higher rate of null allele occurrence $(73 \%)$ than markers that were identified in subsp. variegata $(42 \%)$. A high proportion of nulls was expected in this mapping population both because of the width of the cross, and the expected divergence in priming site sequence between Eucalyptus and Corymbia.

\section{Parental maps}

The maternal framework map had a total length of 399 cM Kosambi (K), was comprised of 42 linked markers in 13 groups, with an average map interval of $9.7 \mathrm{cM}$ $\mathrm{K}$ (Table 3a; Map not shown). The paternal framework map had a total length of $489 \mathrm{cM} \mathrm{K}$, was comprised of 46 linked markers in 13 groups, and had an average map interval of $10.6 \mathrm{cM} \mathrm{K}$ (Table 3; Map not shown).

As expected for two maps based on largely overlapping data sets, synteny and colinearity was extensive. The two maps were entirely collinear; however there were two instances were synteny was imperfect, largely due to markers segregating uniquely in the maternal or paternal datasets. Maternal and paternal homologues were identified for all groups except one pair in the paternal map (Group 10; EMBRA0040m \& EMCRC 0040) and Group 2a (EMCRC0054, EMCRC0033f, EMBRA0011) on the maternal map. Minor differences in multi-locus map distances were also observed between the maps where parent-specific markers mapped uniquely. Missing data was relatively low (1.9\%) for the total dataset $\left(90 \mathrm{~F}_{2}\right.$ offspring plus the two $\mathrm{F}_{1}$ parents and 4 grandparents); the average number of missing data per marker was $1.7 \pm 3.2(\mathrm{SD})$.

Genome lengths were estimated for each parental map at a range of grouping values (LOD 3, 4, 5 and 11; Table $3 b$ ). The genome length estimates for the maternal parent were stable over a range of LODs with an average value of $1643 \mathrm{cM} \mathrm{K}$. Estimates of genome lengths for paternal maps were more variable, but on average, larger (1724 cM K) than the maternal map. The map coverage for the maternal and paternal genomes was 48 and $50 \%$, respectively (Table $3 b$ ).

Meiotic rates of recombination in pollen and ovules differ for many plants (KoRol et al., 1994). In Pinus, recombination rates for pollen can be as much as $43 \%$ higher than for ovules (LEDIG, 1998; MoRAN et al., 1983). This is thought to be adaptive and related to the dispersal mechanism for seed and pollen in pines, as pollen is dispersed much more widely than seed and is likely to encounter much greater environmental heterogeneity. Higher recombination rates in male meiocytes may provide a greater chance of the recombinant offspring being preadapted to the divergent environment that it must survive in. In contrast, Eucalyptus maternal and paternal maps tend to be similar in length (e.g. BuNDOcK et al., 2000; MYBURG et al., 2003). The differential in dispersal distances for pollen and seed in eucalypts is much lower than pines. Eucalypts are animal pollinated with most pollen distributed within $200 \mathrm{~m}$. Seed dispersal is passive in eucalypts, but may be aided by wind and is usually limited to a distance equal to the tree height (< $100 \mathrm{~m}$ ) (House, 1997; PотTs et al., 2003). Corymbia torelliana is an exception as seed may be dispersed by native bees over distances of around $300 \mathrm{~m}$ (WALLACE and TRuEMAN, 1995).

Dispersal mechanisms for Corymbia, as with Eucalyptus, suggest male and female meiotic recombination rates may be similar. The average genome length estimates for Corymbia male and female meiocytes were similar ( $<5 \%$ difference). The larger estimate for the male genome may be due to a lower estimate accuracy at LOD 11 because the small sample size of meioses approaches a lower limit for reliability (CHAKRAVATI et al., 1991). The estimates are also based on $\mathrm{F}_{1}$ hybrids and therefore potentially confounded by differences in recombination rates between parental taxa and recombination shrinkage that may occur in hybrids (KoROL et al., 1994; Stebbins, 1971).

\section{Consensus maps for Corymbia sp}

A framework consensus map was constructed from a single dataset of 64 segregating loci (see methods; Table $3 a$; map not shown). The framework consensus map ( $\mathrm{LOD}=>4$ ) was based on 47 linked markers in 13 groups, with a total map distance of $367 \mathrm{cM} \mathrm{K}$ and average map interval of $8 \mathrm{cM} \mathrm{K}$ (Table $3 a$ ). The shorter map distance for the framework map compared to the parental maps was a consequence of the higher statistical support applied to grouping and ordering that excluded some markers from the framework consensus map. A comprehensive consensus map was also constructed to report linkages with lower statistical support (Grouping $\mathrm{LOD}=>3$ and Jump values $>2$ ) (Figure 2 and Table $3 a$ ). The comprehensive consensus map consisted of 12 groups with a total distance of $417 \mathrm{cM} \mathrm{K}$ and was based on 54 markers, including 9 "accessory" markers that were placed onto the framework map of 45 markers. The total map length of the comprehensive map was longer than the framework map because parent-specific groups were pooled into one map (i.e. groups consisting of markers which were informative for only one of the parents, Groups CM 11 and CM 12). The length of the comprehensive map may be slightly inflated, therefore, because these groups may be homologous, but without markers informative for both parents on these groups it was not possible to determine whether they should be integrated or not. Accessory markers were loci that could not be ordered at "Jump" $<=2$ on the framework maps but nonetheless grouped at LOD $>3$ (EMBRA 0011, EMBRA 007b, EMBRA 039, EMBRA 164a, EMBRA 187, EMBRA 207, CSIROEg 030), and a pair of markers that formed a group at LOD 3 (Group 11; EMCRC 0047 and EMBRA 0014). In addition, on the comprehensive map, two pairs of groups that were not linked at LOD 4 on the framework map, grouped at LOD 3. This linkage was indicated by aligning the pairs vertically (Figure 2 Groups CM1a\&b, CM2a\&b). Group CM1a\&b grouped at LOD 4 but could not be ordered on the framework consensus map, whereas Group CM2a\&b grouped at LOD 3 but could not be ordered on the paternal framework map. Eleven loci were unlinked 
Table 4. - Group 3 on the Corymbia map contains a region where there was a deficit of one class of hybrid offspring genotypes in the $\mathrm{F}_{2}$ generation (in bold). All markers were distorted at $\mathrm{p}$-value $=<0.05$.

\begin{tabular}{|c|c|c|c|c|c|c|c|c|c|c|}
\hline \multirow[t]{2}{*}{ Marker } & \multicolumn{4}{|c|}{ Grandparental genotypes' } & \multirow{2}{*}{$\begin{array}{l}\text { Mat. } \\
F_{I} \\
{ }_{\mathrm{H}}\end{array}$} & \multicolumn{2}{|l|}{ Pat. $F_{I}$} & \multicolumn{3}{|c|}{ Offspring genotypes } \\
\hline & $\mathrm{T} 1 \mathrm{~T} 1$ & V1V1 & $\mathrm{T} 2 \mathrm{~T} 2$ & V2V2 & & $\mathrm{H}$ & (T1T2) & (T2V1) & (T1V2) & (V1V2) \\
\hline EMBRA 214 & $112 / \mathrm{N}$ & $110 / \mathrm{N}$ & $110 / \mathrm{N}$ & $113 / \mathrm{N}$ & $112 / \mathrm{N}$ & $113 / 110$ & 11 & 25 & 30 & 22 \\
\hline EMCRC 039 & $\mathrm{~N} / \mathrm{N}$ & $193 / \mathrm{N}$ & $\mathrm{N} / \mathrm{N}$ & $207 / \mathrm{N}$ & $193 / \mathrm{N}$ & $207 / \mathrm{N}$ & 28 & 11 & 24 & 26 \\
\hline EMBRA 054 & $158 / \mathrm{N}$ & $161 / 169$ & $158 / 163$ & $161 / \mathrm{N}$ & $169 / \mathrm{N}$ & $161 / \mathrm{N}$ & 26 & 10 & 26 & 28 \\
\hline EMCRC 026 & $\mathrm{~N} / 127$ & $113 / 137$ & $111 / \mathrm{N}$ & $105 / 119$ & $137 / \mathrm{N}$ & $105 / \mathrm{N}$ & 19 & 13 & 36 & 21 \\
\hline
\end{tabular}

${ }^{1}$ e.g. $\mathrm{T}_{1} \mathrm{~T}_{1}$ symbolises the grandparental genotype for C. torelliana grandparent 1. Genotypes reported as allele sizes in base-pairs. $\mathrm{N}=$ null allele.

(CSIROEg 094, EMBRA 008, EMBRA 028, EMBRA 1056, EMBRA 145, EMBRA 155, EMBRA 007b, EMCRC 31, EMCRC 44, EMCRC 52, EMCRC 53).

\section{Hybrid inviability}

Marker segregation distortion is a difference in the observed offspring genotype class frequency from that expected based on Mendelian inheritance. The number of markers showing distortion was higher than expected due to sampling error (10 loci in a set of 64 markers $\mathrm{p}$-value $=<0.05$ ). All five of the distorted markers that mapped clustered onto Group 3 (Figure 2). All five markers were deficient in an allele inherited from the maternal parent. Furthermore, at three of the loci (EMCRC 039; EMBRA 054 and EMCRC 026), there was a deficit in one hybrid genotype class (one locus had a backcross configuration and therefore hybrid and parental genotypes could not be distinguished; and the other EMBRA 214 did not fit the pattern, it was deficient in the C. torelliana homozygote $\left(\mathrm{T}_{1} \mathrm{~T}_{2}\right)$ offspring genotype) (Table 4). In particular, there was a deficit of $\mathrm{F}_{2}$ genotypes with an allele from the maternal $\mathrm{F}_{1}$ 's subsp. variegata parent and an allele from the paternal $\mathrm{F}_{1}$ 's $C$. torelliana parent.

Clustering of distorted markers where there is a directional pattern, suggests a biological rather then methodological explanation for marker distortion (KEARSEY and PoONI, 1996). Hybrid dysgenesis and segregation distortion have been features of mapping experiments involving wide crosses in plants, and they tend to be the rule for studies of interspecific hybrids (KoROL et al., 1994; RIESEBERG and LINDER, 1999). Although there may be several methodological or biological explanations for segregation distortion, in our case, hybrid incompatibility would appear to be a likely explanation as there is a deficiency of one hybrid genotypic class. The location of a hybrid inviability locus in the distorted region within Group 3 would account for distortion in linked markers. Moreover, as only one of the hybrid classes was deficient, it suggested a specific interaction between two grandparental backgrounds rather than a more general incompatibility.

Hybrid inviability and advanced generation hybrid breakdown is a key issue for breeders developing eucalypt hybrids and generally relates to the taxonomic distance between the parental species (POTTS and DUNGEY, 2001). High mortality (i.e. 50\%) has been noted in outbred $\mathrm{F}_{2}$ populations of Eucalyptus globulus where the grandparents crossed to produce $\mathrm{F}_{1}$ were from divergent provenances (FREEMAN, 2005). High levels of abnormals
(41-47\%) and low germination (57-61\%) were also reported for backcrosses between $E$. grandis and $E$. globulus, species from different sections of the Symphyomyrtus series (GRIFFIN et al., 2000). In a detailed study of hybrid breakdown, genome wide surveys of the parents of $E$. grandis $\times$ E. globulus backcrosses indicated that in eucalypts, complex multi-genic interactions where likely to account for most post-zygotic isolation (MYBURG et al., 2004).

Based on the experiences with other eucalypt hybrids, the intersectional Corymbia hybrid used in this study would be expected to exhibit pronounced hybrid inviability. There is evidence that both the $\mathrm{F}_{1}$ and $\mathrm{F}_{2}$ exhibit hybrid inviability, although without direct comparative data, it is unclear whether the inviability is more extreme in the $\mathrm{F}_{2}$ (i.e. hybrid breakdown). Low germination $(50 \%)$ and survival of the $\mathrm{F}_{2}$ hybrid family $(76 \%$ and $50 \%$ of germinants survived at 6 and 14 mths respectively) in this study were congruent with hybrid incompatibility. Hybrid inviability was believed to account for high levels of abnormals and mortality in $\mathrm{F}_{1}$ families in the nursery as well as a higher variability in early field growth compared to parental taxa (DICKENSON et al., 2004). In a trial comparing early growth and survival of $F_{1}$ with parental taxa, $F_{1}$ families experienced significantly higher mortality at age 3.5yrs ( $t$ test for independent samples two-tailed $p$-value $=0.017$; av $\pm \mathrm{SE} \mathrm{F}_{1} 55 \pm 4.0 \mathrm{n}=5$; parental families $78 \pm 6.5 \mathrm{n}=5$; from Figure 3 in Dickinson et al. (2004)).

\section{Comparative analysis}

The Corymbia map was compared to a map for Eucalyptus grandis (EM) to evaluate the extent of synteny

Table 5. - Comparative analysis of a Corymbia map (CM) with a Eucalyptus sp. map (EM) (BRONDANI et al., 2002).

\begin{tabular}{c|cc}
\hline Name & CM Group & EM Group \\
\hline EMBRA 001 & 1 & 8 \\
EMBRA 011 & 1 & 1 \\
EMBRA 012 & 1 & 1 \\
EMBRA 020 & 2 & 7 \\
EMBRA 054 & 3 & 5 \\
EMBRA 042 & 5 & 7 \\
EMBRA 007 & 6 & 9 \\
EMBRA 039 & 7 & 11 \\
EMBRA 062 & 7 & 11 \\
EMBRA 040 & 11 & 10 \\
EMBRA 014 & 12 & 8 \\
EMBRA 008 & Unlinked & 6 \\
EMBRA 028 & Unlinked & 6 \\
\hline
\end{tabular}


Table 6. - Genome length, size and physical equivalents for Eucalyptus.

\begin{tabular}{|c|c|c|c|c|c|c|c|}
\hline Species & Sex & $\begin{array}{l}\text { Genome } \\
\text { Length } \\
\text { (cMK) }\end{array}$ & $\begin{array}{l}\text { Grouping } \\
\text { criteria } \\
\text { LOD }\end{array}$ & $\begin{array}{l}\text { Obs. } \\
\text { Map } \\
c M \\
(K)\end{array}$ & $\begin{array}{l}\text { Genome } \\
\text { Size } \\
\text { (Mbp/IC) }\end{array}$ & $\begin{array}{l}\text { IC } \\
\text { physical } \\
\text { equivalent } \\
\text { (kbp) }\end{array}$ & Reference \\
\hline E. grandis & Maternal & 1620 & 5 & 1552 & 641 & 395.7 & (GRATTAPAGLIA \& SEDEROFF 1994) \\
\hline E. urophylla & Paternal & 1156 & 5 & 1101 & 645 & 558.0 & (GRATTAPAGLIA \& SEDEROFF 1994) \\
\hline E. grandis & Maternal & 1331 & 11 & 1335 & 641 & 481.6 & (MYBURG et al. 2003) \\
\hline E. grandis $x$ E. globulus $F I$ & Maternal & 1411 & 11 & 1318 & - & - & (MYBURG et al. 2003) \\
\hline E. globulus & Maternal & 1133 & 4.9 & 701 & 530 & 467.8 & (BUNDOCK et al. 2000) \\
\hline E. globulus & Paternal & 1277 & 4.9 & 1013 & 530 & 415.0 & (BUNDOCK et al. 2000) \\
\hline
\end{tabular}

and colinearity (BRONDANI et al., 2002). Moderate synteny was observed between the Corymbia and Eucalyptus maps. Instances of incongruence in synteny were associated with weak linkage and therefore may be due to incomplete map coverage on the Corymbia map (CM). Corymbia homeologues were identified for eight Eucalyptus groups (Table 5). Thirteen markers were mapped on both maps but only 11 of them were grouped on the Corymbia map (Table 5). This included 5 pairs of syntenic markers from the $E$. grandis map (EM Group 1 EMBRA011 \& EMBRA 012; EM Group 6 EMBRA 008 \& EMBRA 028; EM Group 8 EMBRA 001 \& EMBRA 014; EM; EM Group 7 EMBRA 020 \& EMBRA 042; Group 11 EMBRA 062 \& EMBRA 039). Two of the five pairs were syntenic on both maps (EM Group 1 and CM Group 1; EM Group 11 \& CM Group 4). The linkage between EMBRA 011 \& EMBRA 012 was weak on both the CM (pairwise rf 0.39 LOD 1.78) and EM. Linkage between these two markers was also weak on a map for a second Eucalyptus sp., E. globulus (Multipoint estimate 84.4 cM (K) (Freeman, 2005); (pairwise rf 0.48 LOD 0.07; Pers. Comm. J Freeman). No map distance was available for EMBRA 062 \& EMBRA 039 to compare the estimate from the CM (they were mapped to parental homologues which could not be merged on the EM). In the three instances of non-synteny, marker pairs were loosely linked on the EM (i.e. $>42.6 \mathrm{cM}(\mathrm{K})$ ). Absence of synteny on the CM therefore may be due to low map coverage. There were no instances where colinearity could be examined (i.e. 3 or more markers linked together on the two maps). Increased power to test Corymbia-Eucalyptus synteny must await more extensive map coverage in both taxa.

Genome length estimates for Eucalyptus sp have tended to be similar to or smaller than our estimates for Corymbia (Table $3 b$ and Table 6). Estimates of physical map equivalents for Corymbia tended to be smaller (180-264 kbp/1C) than Eucalyptus sp (395-558 kbp/1C), because of the smaller genome size of Corymbia sp. (GrattaPAGLiA and BradshaW, 1994).

\section{Acknowledgements}

This research was supported by the Australian Research Council, the Queensland DPI - Forestry, the Queensland DPI \& F and the CRC for Sustainable Production Forestry. We thank D. GRATTAPAGLIA for providing unpublished primer sequences and J. FREEMAN for primer aliquots. We thank R. SтокоE for production of the $\mathrm{F}_{2}$ cross, C. Bihua, N. Baker, P. Pomroy, J. Oostenbrink, T. MAGUIRE and L. ScOTT for assistance in the field, nursery or laboratory.

\section{References}

Bonierbale, M. W., R. L. Plaisted and S. D. Tanksley (1988): RFLP maps based on a common set of clones reveal modes of chromosomal evolution in potato and tomato. Genetics 120: 1095-1103.

Brondani, R. P. V., C. Brondani and D. Grattapaglia (2002): Towards a genus-wide reference linkage map for Eucalyptus based exclusively on highly informative microsatellite markers. Molecular Genetics \& Genomics 267: 338-347.

BRONDANi, R. P. V., C. BRondANi, R. TARChini and D. GRATTAPAGLIA (1998): Development, characterisation and mapping of microsatellite markers in Eucalyptus grandis and E. urophylla. Theor. Appl. Genet. 97: 816-827.

Brown, G. R., E. E. Kadel, D. L. Bassoni, K. L. Kiehne, B. Temesgen, J. van Buijtenen, M. M. Sewell, K. A. Marshall and D. B. Neale (2001): Anchored reference loci in Loblolly pine (Pinus taeda L.) for integrating pine genomics. Genetics 159: 799-809.

Bundock, P. C., M. HaYden and R. E. VaillancourT (2000): Linkage maps of Eucalyptus globulus using RAPD and microsatellite markers. Silvae Genetica 49: 223-232.

Chakravarti, A., K. LAsher and J. Reefer (1991): A maximum-likelihood method for estimating genome length using genetic linkage data. Genetics 128: 175-182.

Devey, M., M. M. Sewell, T. L. Uren and D. B. Neale (1999): Comparative mapping in loblolly and radiata pine using RFLP and microsatellite markers. Theor. Appl. Genet. 99: 656-662.

Freeman, J. S., B. M. PotTs, M. Shepherd and R. E. VAILLANCOURT (2006): Parental and consensus linkage maps of Eucalyptus globulus using AFLP and microsatellite markers. Silvae Genetica. In press.

Grattapaglia, D. and H. D. Bradshaw (1994): Nuclear DNA content of commercially important Eucalyptus species and hybrids. Can. J. For. Res. 24: 1074-1078.

Grattapaglia, D. and R. SEDEROFF (1994): Genetic linkage maps of Eucalyptus grandis and Eucalyptus urophylla using a pseudo-testcross: mapping strategy and RAPD markers. Genetics 137: 1121-1137.

Griffin, A., J. Harbard, C. Centurion and P. SAntini (2000): Breeding Eucalyptus grandis x globulus and other inter-specific hybrids with high inviability - problem analysis and experience with Shell forestry projects in Uruguay and Chile, pp. 1-13. In: Hybrid Breeding and Genetics Symposium, edited by H. Dungey, 
M. Dieters and D. NiKLES. Department of Primary Industries, Noosa, Queensland, Australia.

HAQUE, M. S., 1984 Chromosome morphology in 4 species of Eucalyptus L. Her. Cytologia 49: 547-550.

HiLL, K. D., and L. A. S. Johnson (1995): Systematic studies in the eucalypts 7. A revision of the bloodwoods, genus Corymbia (Myrtaceae). Telopea 6: 185-504.

Holmes, W. B. K., F. M. Holmes and H. A. Martin (1983): Fossil Eucalyptus remains from the middle Miocene chalk mountain formation, Warrumbungle Mountains, New South Wales. Proceedings of the Linnean Society of New South Wales 106 (4): 299-310.

House, S. M. (1997): Reproductive biology of eucalypts, pp. 30-55 in Eucalypt Ecology: Individuals to Ecosystems, edited by J. E. Williams and J. C. Z. WoINARSKI. Cambridge University Press, Cambridge.

Hulbert, S., T. Ilott, E. LeGG, S. Lincoln, E. LANDER and R. Michelmore (1988): Genetic analysis of the fungus, Bremia lactucae, using restriction length polymorphism. Genetics 120: 947-958.

Jones, M., R. Stokoe, M. Cross, L. Scott, T. Maguire and M. SHEPHERD (2001): Isolation of microsatellite loci from spotted gum (Corymbia variegata), and crossspecies amplification in Corymbia and Eucalyptus. Molecular Ecology Notes 1: 276-278.

Kearsey, M. J., and H. S. Pooni (1996): Genetic Analysis of Quantitative Traits. Chapman and Hall.

Keats, B., S. Sherman, N. Morton, E. Robson, K. Beutow, H. Cann, P. Cartwright, A. Chakravarti, U. Francke, P. GREen and J. OTt (1991): Guidelines for human linkage maps: an international system for human linkage maps (ISLM, 1990). Genomics 9: $557-560$.

KING, R. (2004): Spatial structure and population genetic variation in a Eucalypt species complex, pp. Griffith University, Brisbane.

Komulainen, P., G. R. Brown, M. Mikmonen, A. Karhu, M. R. Garcia-Gil, D. O'Malley, B. Lee, D. B. Neale and O. SAVOLAINEN (2003): Comparing EST-based genetic maps between Pinus sylvestris and P. taeda. Theor. Appl. Genet. 107: 667-678.

Korol, A. B., I. A. Preygel and S. I. Preygel (1994): Recombination variation and evolution. Chapman and Hall, London.

Ladiges, P. Y., F. Udovic and A. N. DRINnAN (1995): Eucalypt phylogeny - molecules and morphology. Aust. J. Sys. Bot. 8: 483-497.

LAGERCRANTZ, U., and D. LydiATE (1996): Comparative genome mapping in Brassica. Genetics 144: 1903-1910.

Ledig, F. T. (1998): Genetic variation in Pinus, pp. 251-273. In: Ecology and Biogeography of Pinus, edited by D. M. RichaRdson. Cambridge University Press, Cambridge, UK.

LEE, D. (2005): Corymbia species and hybrids: a solution to Queensland hardwood plantations?, pp. 2-5. In: Corymbia Research Meeting: Underpinning development of a profitable hardwood plantation industry in northern Australia by research into Corymbia species and hybrids, edited by D. LEE. DPI\&F, DPI\&F, Gympie Forestry Centre, Qld, Aust.

Marques, C., R. Brondani, D. Grattapaglia and R. SEDEROFF (2002): Conservation and synteny of SSR loci and QTLs for vegetative propagation in four Eucalyptus species. Theor. Appl. Genet. 105: 474-478.

Matsumoto, S. T., M. A. Marin-Morales, C. D. Ruas and P. M. RUAS (2000): Cytogenetic analysis of seven species of Eucalyptus L'Her. (Myrtaceae). Caryologia 53: 205-212.
Moore, G., K. M. Devos, Z. Wang and M. D. Gale (1995): Cereal genome evolution - Grasses, line up and form a circle. Curr. Biol. 5: 737-739.

Moran, G. F., J. C. Bell and A. J. Hilliker (1983): Greater meiotic recombination in male vs. female gametes in Pinus radiata. J Hered 74: 62.

Moran, G. F., K. Groom, T. UREN and M. TORPDAhL (2004): Characterisation of and genetic diversity for trinucleotide microsatellite loci vs dinucleotide microsatellite loci in eucalypts. in review.

Myburg, A., A, R. A. Griffin, R. R. Sederoff and R. W. WhetTEN (2003): Comparative genetic linkage maps of Eucalyptus grandis, Eucalyptus globulus and their $\mathrm{F}_{1}$ hybrid based on a double pseudo-backcross mapping approach. Theor. Appl. Genet. 107: 1028-1042.

MyburG, A. A., C. Vogl, R. A. Griffin, R. R. Sederoff and R. W. WHETTEN (2004): Genetics of postzygotic isolation in eucalyptus: Whole-genome analysis of barriers to introgression in a wide interspecific cross of Eucalyptus grandis and E. globulus. Genetics 166: 1405-1418.

Nelson, C. D., T. L. Kubisiak, M. Stine and W. L. Nance (1994): A genetic linkage map of longleaf pine (Pinus palustris Mill.) based on random amplified polymorphic DNAs. The Journal of Heredity 85: 433-439.

Newbury, H. J. and A. H. PAterson (2003): Genomic colinearity and its application in crop plant improvement, pp. 60-76. In: Plant Molecular Breeding, edited by H. J. NewBURY. Blackwell, Oxford, UK.

O'Brien, S. J., M. Menotti-Raymond, W. J. Murphy, W. G. Nash, J. Wienberg, R. Stanyon, N. G. Copeland, N. A. Jenkins, J. E. Womack and J. A. M. Graves (1999): The promise of comparative genomics in mammals. Science 286: 15.

Peakall, R. and P. E. Smouse (2001): GenAlExV5:Genetic Analysis in Excel. Population genetic software for teaching and research, pp. Australian National University, Canberra.

Potts, B. M., R. C. Barbour, A. B. Hingston and R. E. VAILlancourt (2003): TURNER REVIEW No. 6 Genetic pollution of native eucalypt gene pools - Identifying the risks (vol 51, pg 1, 2003). Aust. J. Bot. 51: 333-NIL 327.

RIESEBERG, L. H. and C. R. LindNeR (1999): Hybrid classification: Insights from genetic map-based studies of experimental hybrids. Ecology 80: 361-370.

RossetTo, M. (2001): Sourcing of SSR Markers from Related Plant Species, pp. 211-224. In: Plant Genotyping: the DNA Fingerprinting of Plants, edited by R. HENRY. CAB International.

RYChlik, W., W. J. Spencer and R. E. RhoAds (1990): Optimisation of the annealing temperature for DNA amplification in vitro. Nucl. Acids Res. 18: 6409-6412.

Steane, D. A., D. Nicolle, G. McKinnon, R. VaillanCOURT and B. РотTs (2002): Higher-level relationships among the eucalypts are resolved by ITS-sequence data. Aust. J. Sys. Bot. 15: 49-62.

Steane, D. A., R. E. Vaillancourt, J. Russell, W. Powell, D. Marshall and B. M. PotTs (2001): Development and characterisation of microsatellite loci in Eucalyptus globulus (Myrtaceae). Silvae Genetica 50: 89-91.

StebBins, G. L. (1971): Chromosomal Evolution in Higher Plants. Edward Arnold, London.

Udovicic, F., G. McFadden and P. Y. LAdiges (1995): Phylogeny of Eucalyptus and Angophora based on 5S rDNA spacer sequence data. Molecular Phylogenetics and Evolution 4: 247-256. 
VAN OOIJEN, J. and R. VoORRIPS (2001): JoinMap 3.0 Software for the calculation of genetic linkage maps, pp. Plant Research International B.V., Wageningen.

VOORRIPS, R. (2001): MapChart version 2.0: Windows software for the graphical presentation of linkage groups and QTLs, pp. Plant Research International, Wageningen, The Netherlands.

Wallace, H. and S. J. TRueman (1995): Dispersal of seeds of Eucalyptus torelliana by the stingless bee, Trigona Carbonaria. Oecologia 104: 12-16.

\title{
Short Note: High Throughput Microsatellite Genotyping in Oak Species
}

\author{
By O. LepAis, V. LÉGER and S. GeRBeR*) \\ UMR BIOGECO, INRA-Université Bordeaux I, 69 route d'Arcachon, 33612 Cestas Cedex, France
}

(Received 21 ${ }^{\text {st }}$ March 2006)

\begin{abstract}
Microsatellites are widely used markers for multiple purposes in oaks. We describe a complete procedure for cheap DNA extraction and fast microsatellites genotyping by multiplex PCR. 10 loci were selected to form two multiplex kits including three loci that show a high differentiation between Quercus robur and Q. petraea. The loci were tested in three oak species and show a high mean genetic diversity of 0.84 . The cumulative exclusion probability for parentage analysis was 0.999977 for single parent and 1.0 for paternity. Finally, the relatively high differentiation coefficient $($ Gst $=0.04)$ will facilitate species assignment based on genotypes in oaks.
\end{abstract}

Key words: microsatellites; multiplex PCR; Quercus; genetic assignment; parentage analysis.

Oaks are common species in a large part of the world and are involved in an increasing number of genetic studies concerning especially population genetic structure and gene flow. New powerful methods for analysing multilocus genetics data allow inference about past demographic events, genetics assignment or detection of selection (CHIKHI and BRUFORD, 2005). We took advantage of technical laboratory progresses to increase availability of multilocus microsatellites data. Combining multiplex PCR and automated capillary sequencer speed up the genotyping compared to silver straining gel or gel plate automated sequencer. In the same time it decreases cost of genotyping and allows to reach high loci number analysis which is needed for high resolution studies in natural populations. In this short note, we present a protocol that allows fast DNA extraction and genotyping for 10 microsatellites in two multiplex PCR.

We used a modified protocol based on CTAB/ dichloromethane (DUMOLIN et al., 1995) allowing DNA extraction in 96 wells plates format. This modification provides high quality DNA extraction from 192 individuals in one day at a low cost compared to commercial kits.

\footnotetext{
*) Communicating author: SopHIE GERBER. Telephone: 0033557122830. Fax: 0033-557122881. Email: gerber@pierroton. inra.fr
}

One centimeter square of leave or three to five buds are cut into small pieces and put in a $1.2 \mathrm{~mL}$ microtube (Qiagen, Cat. No. 19560) with two $2 \mathrm{~mm}$ steel balls, a small amount of insoluble PVP and alumina, $100 \mu \mathrm{L}$ of extraction buffer (CTAB 20 mg.mL ${ }^{-1}$, EDTA (pH 8) $0.02 \mathrm{M}$, Tris $\mathrm{HCl}(\mathrm{pH}$ 8) $0.1 \mathrm{M}, \mathrm{NaCl} 1.4 \mathrm{M}$, soluble PVP $10 \mathrm{mg} . \mathrm{mL}^{-1}$ ). Vegetable tissues and $300 \mu \mathrm{L}$ of extraction buffer are ground in a Retsch-Mill at 30 vibrations per second for $1 \mathrm{~min}$ for each side. The microtubes are incubated at $55^{\circ} \mathrm{C}$ for 1 hour in a vertical position with shaking. After cooling, $300 \mu \mathrm{L}$ of dichloromethane is added and microtubes are shaken. After 20 minutes of centrifugation at $6200 \mathrm{rpm}$ and $4{ }^{\circ} \mathrm{C}$, the upperphase is transferred in new microtubes, $300 \mu \mathrm{L}$ of cold isopropanol is added and after shaking the microtubes are placed at $-20^{\circ} \mathrm{C}$ for 1 hour in a vertical position. After a centrifugation step of 20 minutes at $6200 \mathrm{rpm}$ and $4{ }^{\circ} \mathrm{C}$, the supernatant is removed, $500 \mu \mathrm{L}$ of ethanol is added and microtubes are shaken before centrifugation for 20 minutes at $6200 \mathrm{rpm}$ and $4^{\circ} \mathrm{C}$. Supernatant is then removed and the pellet is dried in a vacuum system concentrator for 15 minutes at $55^{\circ} \mathrm{C}$. Finally the pellet is resuspended in $50 \mu \mathrm{L}$ of pure water. To avoid lost of DNA pellet when removing the upperphase after each centrifugation step, microtubes are kept on ice.

We selected microsatellites loci that are highly differentiated between Quercus robur and Q. petraea (ScoтTISAINTAGNE et al., 2004; P. Goikoetxea, unpublished data). Before multiplexing, primers were checked for primer-primer interaction using the AutoDimer software (VALLONE and BUTLER, 2004). One set, called KIT1, comprises the five following loci QrZAG11, QrZAG39, QrZAG96, QrZAG112 and QpZAG110 and the second one, five others (KIT2): QrZAG5, QrZAG7, QrZAG20, QrZAG65 and QrZAG87 (KAMPFER et al., 1997; STEINKELLNER et al., 1997). On the 10 selected microsatellites, 7 are unlinked (Table 1). Each forward primer was marked with a fluorescent dye (MWG and Applied Biosystems) as shown in Table 1. PCR were carried out in a final volume of $15 \mu \mathrm{L}$ including $5 \mu \mathrm{L}$ of $1 / 50$ to $1 / 200$ diluted DNA, depending on DNA concentration 